\title{
NOX2 inhibition reduces oxidative stress and prolongs survival in murine KRAS-induced myeloproliferative disease
}

\author{
Ebru Aydin ${ }^{1} \cdot$ Alexander Hallner $^{1} \cdot$ Hanna Grauers Wiktorin ${ }^{1} \cdot$ Anna Staffas $^{1,2} \cdot$ Kristoffer Hellstrand $^{1} \cdot$ Anna Martner $^{1}$
}

Received: 6 April 2018 / Revised: 16 August 2018 / Accepted: 13 September 2018 / Published online: 15 October 2018

(c) The Author(s) 2018. This article is published with open access

\begin{abstract}
Mutations leading to constitutive RAS activation contribute in myeloid leukemogenesis. RAS mutations in myeloid cells are accompanied by excessive formation of reactive oxygen species (ROS), but the source of ROS and their role for the initiation and progression of leukemia have not been clearly defined. To determine the role of NOX2-derived ROS in RASdriven leukemia, double transgenic LSL-Kras ${ }^{\mathrm{G} 12 \mathrm{D}} \times \mathrm{Mx1}$-Cre mice expressing oncogenic KRAS in hematopoietic cells (M$\operatorname{Kras}^{\mathrm{G} 12 \mathrm{D}}$ ) were treated with $N^{\alpha}$-methyl-histamine $(N \mathrm{MH})$ that targeted the production of NOX2-derived ROS in leukemic cells by agonist activity at histamine $\mathrm{H}_{2}$ receptors. M-Kras ${ }^{\mathrm{G} 12 \mathrm{D}}$ mice developed myeloid leukemia comprising mature

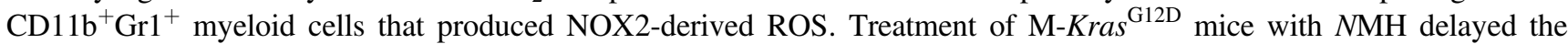
development of myeloproliferative disease and prolonged survival. In addition, $N \mathrm{MH}$-treated $\mathrm{M}-\mathrm{Kras}^{\mathrm{G} 12 \mathrm{D}}$ mice showed reduction of intracellular ROS along with reduced DNA oxidation and reduced occurence of double-stranded DNA breaks in myeloid cells. The in vivo expansion of leukemia was markedly reduced in triple transgenic mice where KRAS was

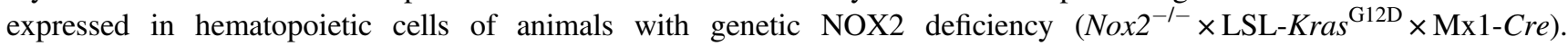
Treatment with $N \mathrm{MH}$ did not alter in vivo expansion of leukemia in these NOX2-deficient transgenic mice. We propose that NOX2-derived ROS may contribute to the progression of KRAS-induced leukemia and that strategies to target NOX2 merit further evaluation in $R A S$-mutated hematopoietic cancer.
\end{abstract}

\section{Introduction}

RAS proteins are GTPases that transmit growth factor receptor signals to several downstream effector pathways, including the PI3 kinase (PI3K)-AKT and the RAF-MEKERK pathways, to trigger the proliferation, survival, growth, and differentiation of cells. In its active form, RAS is loaded with GTP, but the intrinsic GTPase activity of wild-type (WT) RAS leads to self-inactivation once the

Electronic supplementary material The online version of this article (https://doi.org/10.1038/s41388-018-0528-1) contains supplementary material, which is available to authorized users.

Anna Martner

anna.martner@gu.se

1 TIMM Laboratory, Sahlgrenska Cancer Center, University of Gothenburg, 41390 Gothenburg, Sweden

2 Department of Clinical Chemistry and Transfusion Medicine, Sahlgrenska Academy, University of Gothenburg, 41345 Gothenburg, Sweden growth factor signal ceases. $R A S$ mutations resulting in loss of GTPase function entail constitutive, non-growth factordependent RAS signaling that contributes to malignant transformation. RAS mutations leading to constitutive RAS activation are observed in $\sim 30 \%$ of cancer patients [1] and in $15 \%$ of patients with hematopoietic malignancies [2].

$K R A S$ is one of three homologues of the RAS family of oncogenes in addition to NRAS and HRAS. Although these isoforms encode similar proteins, different variants of mutated $R A S$ dominate, for unknown reasons, in different forms of cancer [3, 4]. HRAS mutations are thus rarely found in myeloid malignancies, whereas mutations leading to oncogenic KRAS or NRAS activation occur in $~ 40 \%$ of cases with chronic myelomonocytic leukemia [5] and in $20 \%$ of cases of monocytic (FAB classes M4 and M5) forms of acute myeloid leukemia (AML) [5-7].

Compounds that covalently attach KRAS G12C [8], antagonists of RAS-membrane association and downstream effector signaling $[9,10]$ and strategies to target downstream signaling of KRAS by inhibition of PI3K/Akt or Raf/ MEK/ERK have shown promise in preclinical models of RAS-induced cancer [11-14]. For the present study, we 
A

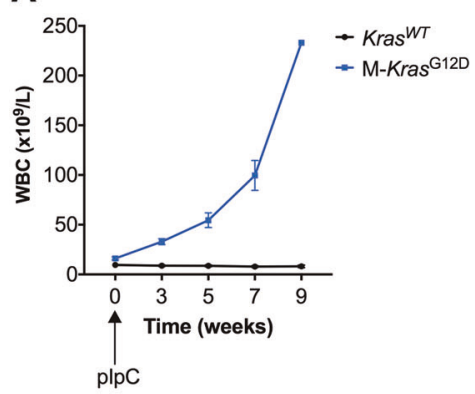

B

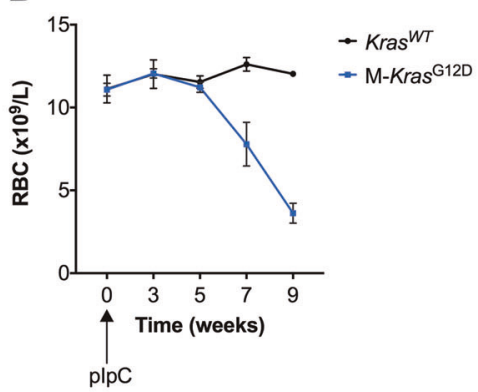

C

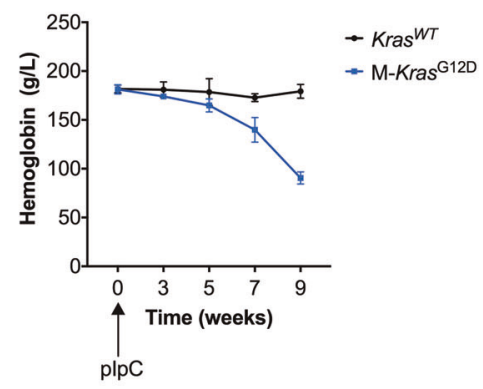

D

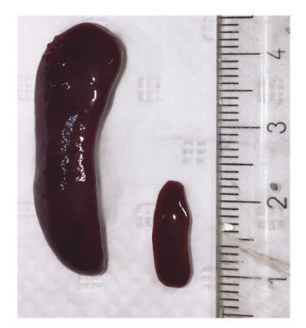

$E$

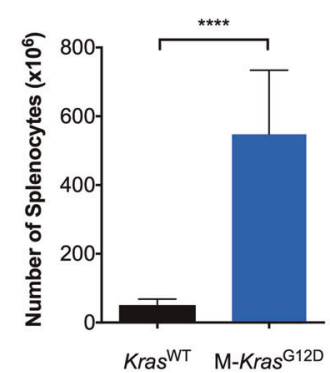

Kras $^{\mathrm{WT}} \mathrm{M}-\mathrm{Kras}^{\mathrm{G} 12 \mathrm{D}}$
F Kras $^{\mathrm{WT}} \quad \mathrm{M}-\mathrm{Kras}^{\mathrm{G} 12 \mathrm{D}}$
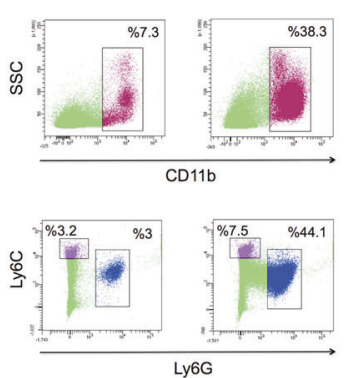

G

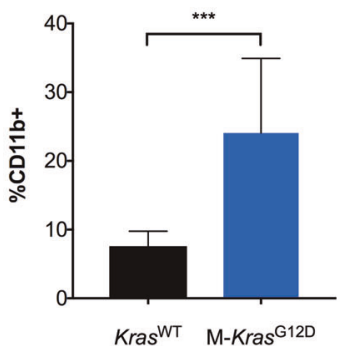

a Kras $^{\mathrm{WT}}$ mouse (right). e Number of splenocytes isolated from endpoint $\mathrm{M}-\mathrm{Kras}^{\mathrm{G} 12 \mathrm{D}}$ mice (blue, $n=17$ ). The splenocyte counts from Kras $^{\mathrm{WT}}$ mice (black, $n=10$ ) are shown for comparison ( $t$-test). $\mathbf{f}$ FACS plots showing expansion of $\mathrm{CD}_{11 \mathrm{~b}^{+}} \mathrm{Ly}_{6 \mathrm{G}} \mathrm{G}^{+}$and $\mathrm{Ly}_{6 \mathrm{C}} \mathrm{C}^{+}$ myeloid cells in the spleen of a representative endpoint $\mathrm{M}-$ Kras $^{\mathrm{G} 12 \mathrm{D}}$ mouse and a Kras ${ }^{\mathrm{WT}}$ mouse. $g$ Frequency of $\mathrm{CD} 11 \mathrm{~b}^{+}$-infiltrating cells among live cells in the spleens of endpoint $\mathrm{M}-\mathrm{Kras}^{\mathrm{G}}{ }^{12 \mathrm{D}}$ mice (blue, $n$ $=10)$ and $\operatorname{Kras}^{\mathrm{WT}}$ mice (black, $\left.n=8\right)\left(t\right.$ test). ${ }^{*} p<0.05,{ }^{*} p<0.01$, $* * * p<0.001$

pharmacological inhibition of NOX2 reduces oxidative stress to maintain genomic stability in Kras-mutated cells.

asked if the production of reactive oxygen species (ROS), a downstream event that appears to be enhanced by RAS signaling, may contribute in RAS-induced leukemogenesis. Although earlier studies show that $R A S$ mutations trigger enhanced ROS levels [15-21], the contribution by ROS generated during mitochondrial respiration or by the enzymatic formation of ROS via the NADPH oxidase (NOX) isoforms NOX1, NOX2, or NOX4 remains controversial $[15,17,22-24]$.

To address the role of NOX2, which is the dominant source of enzymatically derived ROS in normal and leukemic myeloid cells [25-28], in KRAS-driven leukemia we utilized double transgenic LSL-Kras ${ }^{\mathrm{G} 12 \mathrm{D}} \times \mathrm{Mx1}$-Cre mice where hematopoiesis was biased toward the $\mathrm{NOX}^{+}$granulocyte/monocyte linage. We also created triple transgenic Nox $2^{-1-} \times$ LSL-Kras ${ }^{\mathrm{G} 12 \mathrm{D}} \times \mathrm{Mx1-Cre}$ mice that were devoid of NOX2-dependent ROS formation. The double and triple transgenic mice were treated with $N^{\alpha}$-methyl-histamine $(N \mathrm{MH})$ that inhibits NOX2 activity via agonist activity at histamine type 2 receptors $\left(\mathrm{H}_{2} \mathrm{Rs}\right)$. $N \mathrm{MH}$ is a major histamine metabolite with reduced activity at histamine type 1 receptors $\left(\mathrm{H}_{1} \mathrm{Rs}\right)$ and increased affinity at type 2 and type 3 receptors [29]. Our results imply a role for NOX2 in KRASinduced myeloproliferation and suggest that

\section{Results}

\section{LSL-Kras $^{G 12 D} \times$ Mx1-Cre mice develop myeloproliferative disease comprising mature $\mathrm{CD}_{11 \mathrm{~b}}{ }^{+} \mathrm{Gr}^{+}$myeloid cells}

$\mathrm{LSL}_{-K r a s}^{\mathrm{G} 12 \mathrm{D}}$ and Mx1-Cre mice were mated to generate double transgenic LSL-Kras ${ }^{\mathrm{G} 12 \mathrm{D}} \times \mathrm{Mx1}-\mathrm{Cre}\left(\mathrm{M}-\mathrm{Kras}^{\mathrm{G} 12 \mathrm{D}}\right)$ pups. Kras ${ }^{\mathrm{G} 12 \mathrm{D}}$ expression was induced in 3-6-week old $\mathrm{M}-\operatorname{Kras}^{\mathrm{G} 12 \mathrm{D}}$ pups by polyinosinic-polycytidylic acid (pIpC) injections. In accordance with previous studies [30] the white blood cell (WBC) levels rose beginning $\sim 3$ weeks after pIpC injections followed by a significant drop in red blood cell (RBC) counts and in hemoglobin levels (Fig. 1a-c). At the study endpoint, i.e., 3-10 weeks after $\mathrm{pIpC}$ injections, the spleens of the M-Kras ${ }^{\mathrm{G} 12 \mathrm{D}}$ mice were markedly enlarged compared with spleens of WT littermates (Fig. 1d). The splenomegaly translated into high counts of splenocytes in $\mathrm{M}-\operatorname{Kras}^{\mathrm{G} 12 \mathrm{D}}$ mice (Fig. 1e) and spleens of M-Kras ${ }^{\mathrm{G} 12 \mathrm{D}}$ mice were infiltrated by $\mathrm{CD} 11 \mathrm{~b}^{+} \mathrm{Gr} 1^{+}$myeloid cells (Fig. 1f, g). 
The bone marrow of endpoint $\mathrm{M}-\mathrm{Kras}^{\mathrm{G} 12 \mathrm{D}}$ mice contained a higher percentage of $\mathrm{CD} 11 \mathrm{~b}^{+} \mathrm{Gr} 1^{+}$cells compared with WT littermates ( $p=0.03, n=15$ for each group. $t$ test). Although all mice showed signs of myeloproliferative disease, $\sim 40 \%$ of the $\mathrm{M}-\mathrm{Kras}^{\mathrm{G} 12 \mathrm{D}}$ mice also developed T-cell leukemia, as determined by presence of CD4 and CD8 double-positive $\mathrm{T}$ cells along with enlarged thymuses (data not shown).

\section{NMH inhibits ROS formation from myeloid M- Kras $^{\mathrm{G} 12 \mathrm{D}}$ cells}

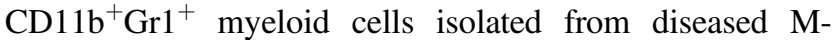
$\mathrm{Kras}^{\mathrm{G} 12 \mathrm{D}}$ mice were stimulated with the NOX2-inducer WKYMVm [31] in the presence or absence of $N M H$ for analysis of superoxide anion, monitored continuously by chemiluminescence. It was observed that $\mathrm{CD}_{11} \mathrm{~b}^{+} \mathrm{Gr} 1^{+}$ cells produced significant amounts of superoxide anion in response to WKYMVm, which was dose-dependently targeted by $N M H$ (Fig. 2a). $N M H$ exerts selectively agonist activity at $\mathrm{H}_{2}$ receptor $\left(\mathrm{H}_{2} \mathrm{R}\right)$ [29] and ranitidine, a $\mathrm{H}_{2} \mathrm{R}$ specific antagonist [32], completely prevented the inhibitory effect of $N M H$ on WKYMVm-induced superoxide anion formation (Fig. 2b).

\section{NMH delays the development of myeloproliferative disease and prolongs the survival of M-Kras ${ }^{\mathrm{G} 12 \mathrm{D}}$ mice}

One week after the first $\mathrm{pIpC}$ injection, $\mathrm{M}-\mathrm{Kras}^{\mathrm{G} 12 \mathrm{D}}$ mice were randomized to receive intraperitoneal (i.p.) injections
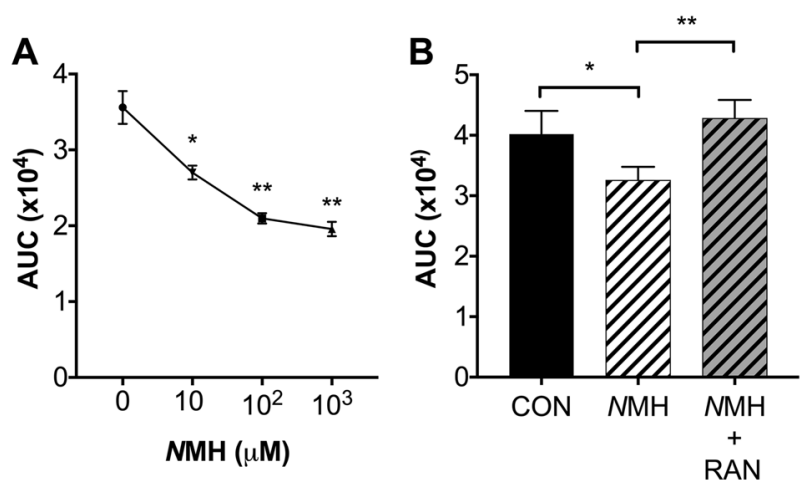

Fig. $2 \mathrm{NMH}$ inhibits ROS production by $\mathrm{Gr}^{+}$cells from M-Kras ${ }^{\mathrm{G} 12 \mathrm{D}}$ mice. a Two-hundred thousand $\mathrm{Gr}^{+}$cells from the spleen of $\mathrm{M}$ $\operatorname{Kras}^{\mathrm{G} 12 \mathrm{D}}$ mice were stimulated with WKYMVm $\left(5 \times 10^{-7} \mathrm{M}\right)$ in the presence or absence of $N \mathrm{MH}$ at indicated concentrations. Superoxide anion production was measured continuously during $12 \mathrm{~min}$ by chemiluminescence and is displayed as area under the curve (AUC) $(n=3$ for each concentration). b Superoxide production from $\mathrm{Gr}^{+}$cells from the spleens of M-Kras ${ }^{\mathrm{G} 12 \mathrm{D}}$ mice in response to stimulation with WKYMVm $\left(5 \times 10^{-7} \mathrm{M}\right)$ in the presence or absence of $N M H(100 \mu \mathrm{M})$ and the $\mathrm{H}_{2} \mathrm{R}$ antagonist ranitidine $(\mathrm{RAN} ; 100 \mu \mathrm{M})(n=4$ for each group, $t$ test). $* p<0.05, * * p<0.01, * * * p<0.001$ of $N \mathrm{MH}(250 \mu \mathrm{g} / \mathrm{mouse})$ or vehicle $(\mathrm{NaCl})$ thrice weekly for 5 weeks (Fig. 3a). Mice receiving $N M H$ experienced a milder course of disease with better mobility, fur condition, and posture compared with control animals (data not shown). Treatment with $N \mathrm{MH}$ also improved the survival of M-Kras ${ }^{\mathrm{G} 12 \mathrm{D}}$ mice (Fig. 3b) and delayed the development of myeloid leukemia (Fig. 3c). While on treatment, 3 out of 28 $\mathrm{M}-\operatorname{Kras}^{\mathrm{G} 12 \mathrm{D}}$ mice in the $\mathrm{NMH}$-group died of leukemia versus $14 / 29$ mice in the control group ( $p=0.003$, Fisher's exact test).

\section{Role of NOX2 for the anti-leukemic efficacy of NMH in $\mathrm{M}-\mathrm{Kras}^{\mathrm{G} 12 \mathrm{D}}$ mice}

To further clarify the role of NOX2 for the observed effects of $N \mathrm{MH}$ on the development of Kras-induced leukemia and survival, we generated triple transgenic mice that expressed the Mx1-Cre-inducible LSL-Kras ${ }^{\mathrm{G} 12 \mathrm{D}}$ on a NOX2-deficient

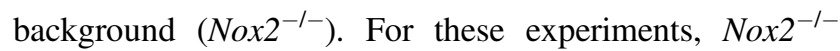
mice were mated with LSL-Kras ${ }^{\mathrm{G} 12 \mathrm{D}}$ and $\mathrm{Mx} 1-\mathrm{Cre}$ mice followed by at least three backcrosses. The knockout of the Nox2 gene was confirmed by genotyping and by the absence of NOX2-dependent superoxide production (Supplementary figure $1 \mathrm{~A}, \mathrm{~B})$.

We observed significant myeloproliferation and anemia

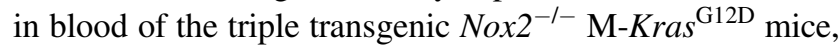
suggesting that leukemia was successfully induced also in the absence of NOX2 (Supplementary figure 2). The increase in WBC counts was however markedly reduced in

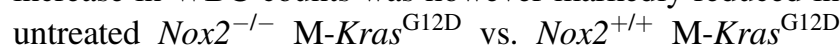
mice ( $p=0.02$ at 5 weeks, $p=0.003$ at 7 weeks, $t$ test; Fig. $3 \mathrm{c}$, e). In vivo treatment with $N \mathrm{MH}$ did not delay or reduce the development of leukemia in the triple transgenic Nox $2^{-l-}$ mice (Fig. 3d, e). Knockout of Nox2 did not translate into a survival benefit in $\mathrm{M}-\mathrm{Kras}^{\mathrm{G} 12 \mathrm{D}}$ mice. The triple transgenic mice showed increased susceptibility to infection in the form of abscesses in skin, liver or lungs. Visible infections were thus observed in $\sim 45 \%$ of Nox $2^{-l-}$ $\mathrm{M}-\mathrm{Kras}^{\mathrm{G} 12 \mathrm{D}}$ mice during the course of the study, compared with $3 \%$ of double transgenic $\mathrm{Nox}^{+/+} \mathrm{M}-\mathrm{Kras}^{\mathrm{G} 12 \mathrm{D}}$ mice and $3 \%$ of $\mathrm{Nox}^{-1-} \mathrm{Kras}^{\mathrm{WT}}$ mice. The incidence of visible infections was not significantly affected by $N \mathrm{MH}$ treatment (data not shown).

\section{NOX2 inhibition reduces intracellular ROS levels in myeloid cells}

To determine effects of in vivo treatment with $N \mathrm{MH}$ on the formation of ROS in accumulating myeloid leukemic cells, peripheral blood was recovered from control and $\mathrm{NMH}-$

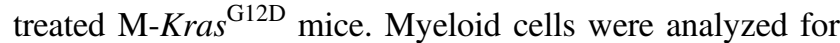
intracellular ROS content using the 2',7' -dichlorofluorescin diacetate (DCFDA) probe. It was observed that the 
Fig. $3 \mathrm{NMH}$ delays the development of leukemia in NOX2-sufficent M-Kras ${ }^{\mathrm{G} 12 \mathrm{D}}$ mice. a shows the experimental design of the in vivo experiments. b-c Kras expression in hematopoietic cells (M-Kras ${ }^{\mathrm{G} 12 \mathrm{D}}$ ) was induced in double transgenic mice (LSLKras $^{\mathrm{G} 12 \mathrm{D}} \times \mathrm{Mx} 1-\mathrm{Cre}$ ) by pIpC injections. Mice were treated with $N \mathrm{MH}$ (red line) or $\mathrm{NaCl}$ (CON; blue line) i.p. thrice weekly for 5 weeks. b Survival of control (blue line) and $\mathrm{NMH}$ treated (red line) mice $(n=28$ for $N \mathrm{HM}, n=29$ for controls; logrank test). c White blood cell counts (WBC) in peripheral blood during disease progression in $\mathrm{NMH}$-treated (red line) and control (blue line) mice ( $n=26$ for each group, $t$ test). d, e Kras expression was induced in triple transgenic mice $\left(\mathrm{Nox}^{-l-}\right.$, LSL$\mathrm{Kras}^{\mathrm{G} 12 \mathrm{D}}$, and Mx1-Cre) denoted Nox $2^{-l-}$ M-Kras ${ }^{\mathrm{G} 12 \mathrm{D}}$ mice. Mice were treated with $N \mathrm{MH}$ (red line) or $\mathrm{NaCl}(\mathrm{CON}$; blue line) i.p. thrice weekly. d Survival of control (blue line) and $\mathrm{NMH}$-treated (red line) triple transgenic mice $(n=8$ for controls and $n=7$ for the $N \mathrm{MH}$ treated group; logrank test). e Counts of white blood cells in blood during progression of disease of control (blue line) and $N \mathrm{MH}$-treated (red line) mice ( $n$ $=8$ for controls and $n=7$ for $N \mathrm{MH}$-treated mice; $t$ test). $* p<$ $0.05, * * p<0.01, * * * p<0.001$
A 4-7 week old

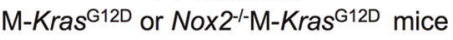

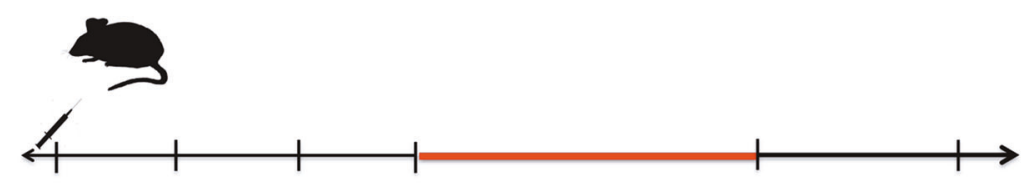

Day (+1) Day (+3) Day (+5) Day (+7)

Day (+42) When moribund
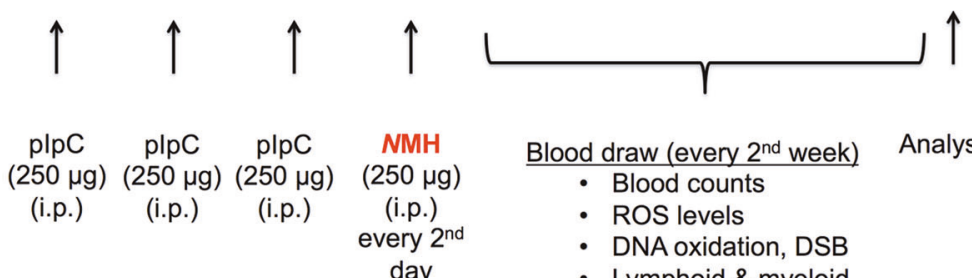
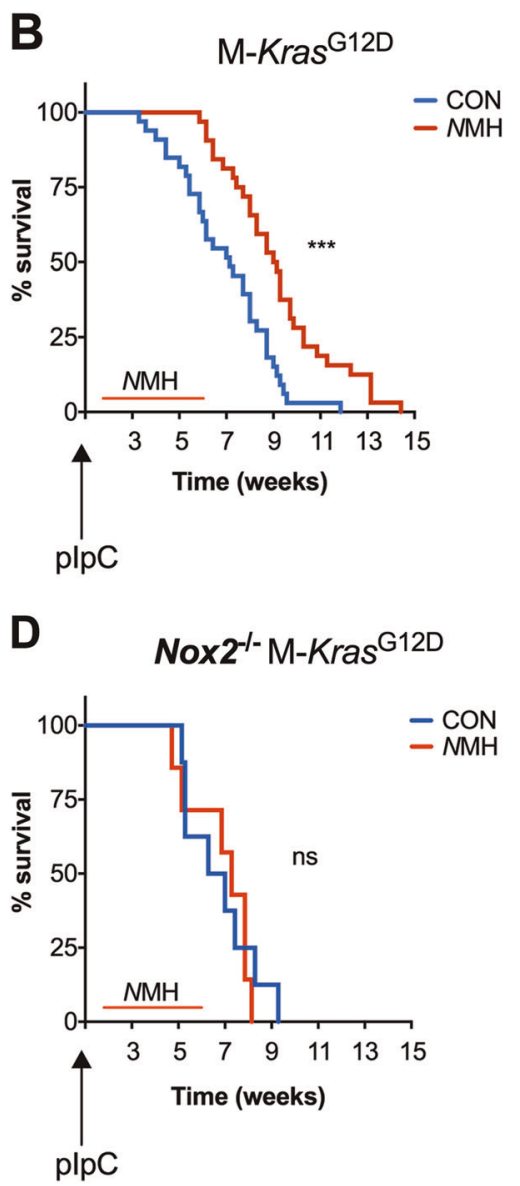
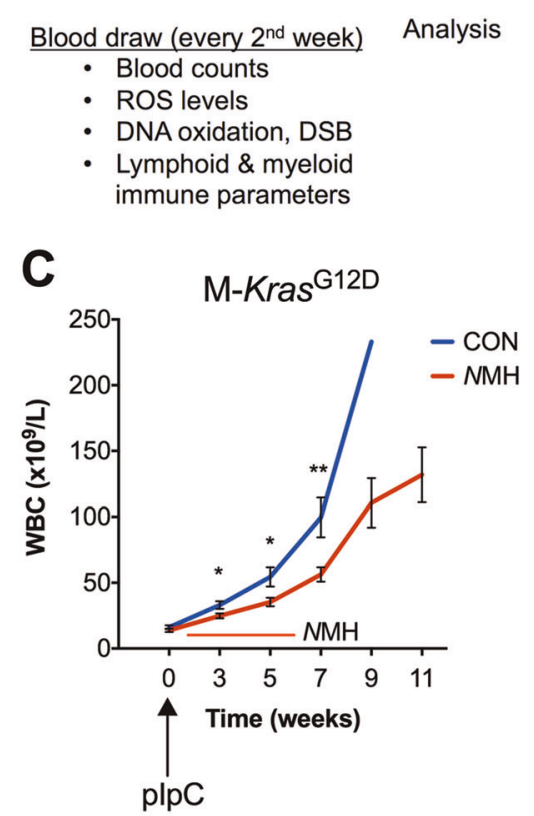

E Nox2-1-M-Kras ${ }^{\mathrm{G} 12 \mathrm{D}}$

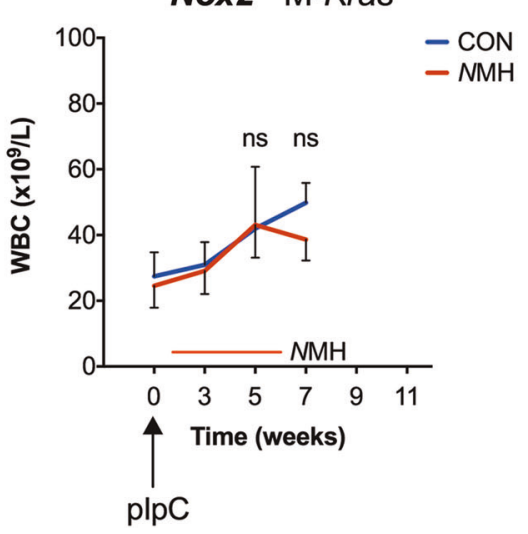

intracellular ROS levels in CD11 $\mathrm{b}^{+}$myeloid cells increased significantly during disease progression (Fig. 4a). In accordance, myeloid cells isolated from the bone marrow and spleen of endpoint $\mathrm{Kras}^{\mathrm{G} 12 \mathrm{D}}$ mice showed significantly higher DCFDA staining compared with myeloid cells from Kras $^{\text {WT }}$ bone marrow and spleen (Supplementary figure 3A, D). Furthermore, systemic treatment with $\mathrm{NMH}$ significantly reduced the accumulation of ROS in KRASexpressing myeloid cells at 3 and 5 weeks after pIpC injections (Fig. 4a). Myeloid cells from $\mathrm{Nox}^{-/-}$M$\operatorname{Kras}^{\mathrm{G} 12 \mathrm{D}}$ mice expressed significantly lower intracellular ROS levels compared with M-Kras ${ }^{\mathrm{G} 12 \mathrm{D}}$ mice with intact NOX2 at 5 weeks after pIpC injection (Fig. 4d), and the ROS levels were unaffected by systemic $N M H$ treatment in 

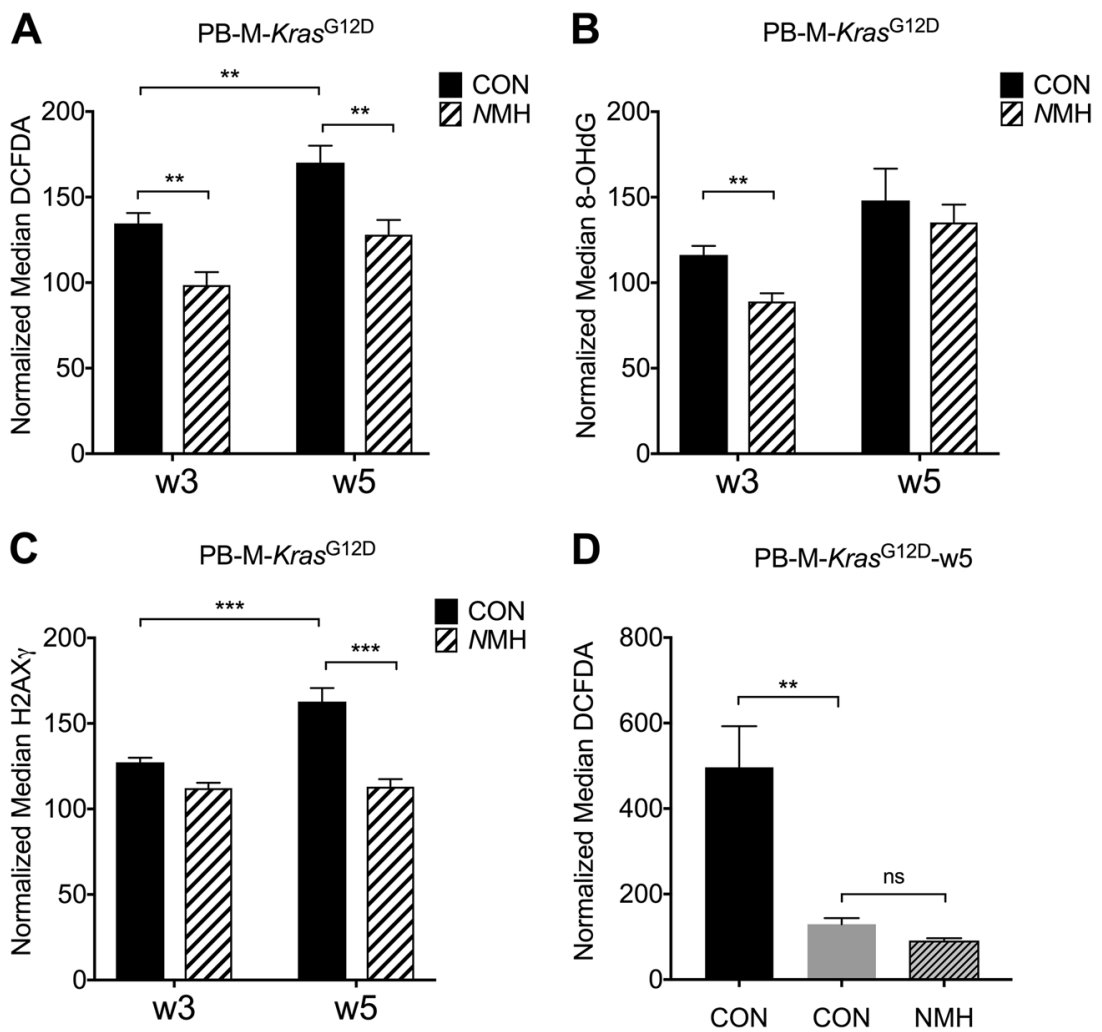

D PB-M-Kras ${ }^{\mathrm{G} 12 \mathrm{D}-\mathrm{w} 5}$

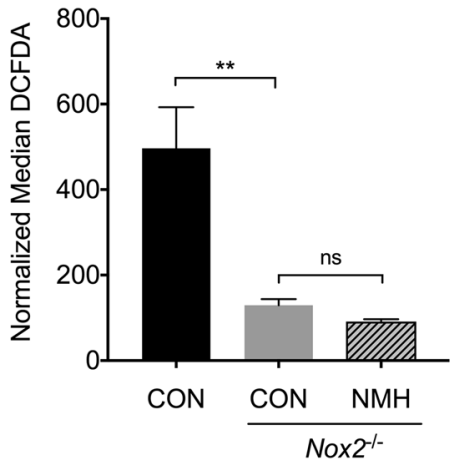

Fig. 4 Treatment of mice with $N \mathrm{MH}$ maintains genomic integrity. Expression of mutated Kras in hematopoietic cells was induced in a-c double transgenic mice (LSL-Kras ${ }^{\mathrm{G} 2 \mathrm{D}} \times \mathrm{Mx} 1-\mathrm{Cre}$; M-Kras ${ }^{\mathrm{G} 12 \mathrm{D}}$ ) and d triple transgenic mice $\left(\mathrm{Nox}^{-/-}\right.$, LSL-Kras $^{\mathrm{G} 12 \mathrm{D}}$, and Mx1-Cre; Nox2 ${ }_{-1-} \mathrm{M}-\mathrm{Kras}^{\mathrm{G12D}}$ ) by pIpC injections. Mice were treated with $\mathrm{NMH}$ (250 $\mu \mathrm{g} /$ mouse; red) or $\mathrm{NaCl}(\mathrm{CON}$; blue) i.p. thrice weekly for 5 weeks. For M-Kras ${ }^{\mathrm{G} 12 \mathrm{D}}$ mice, peripheral blood samples collected after 3 and 5 weeks (w3, w5) were analyzed for a intracellular ROS levels in CD11 $\mathrm{b}^{+}$cells by use of DCFDA staining $(n=5-7)$, $\mathbf{b}$ oxidized DNA by measurement of 8-OHdG expression in myeloid cells $(n=7-8)$, and c double-stranded DNA breaks reflected by the expression of gamma-H2AX in myeloid cells $(n=7-8$ for each week and each group). In a-c, the stainings for DCFDA, 8-OHdG, and

these triple transgenic mice (Fig. 4d). In addition, myeloid cells from endpoint $\mathrm{Nox}^{-/-} \mathrm{M}-\mathrm{Kras}^{\mathrm{G} 12 \mathrm{D}}$ mice expressed significantly lower levels of intracellular ROS compared with $\mathrm{Nox}^{+/+} \mathrm{M}-\mathrm{Kras}^{\mathrm{G} 12 \mathrm{D}}$ mice at a corresponding stage of disease (Supplementary figure 3A, D).

\section{Treatment with NMH does not impact on NK cell or $T$ cell counts in M-Kras ${ }^{\mathrm{G} 12 \mathrm{D}}$ mice}

Pharmacological inhibition of NOX2 was previously shown to reduce the release of extracellular ROS and thereby protect adjacent anti-neoplastic lymphocytes such as NK cells and T cells from ROS-induced inactivation [33, 34]. To investigate if the reduced ROS levels in myeloid

gamma-H2AX were normalized against staining of myeloid cells in blood of Kras ${ }^{\text {WT }}$ mice. The increases in staining levels between w3w5 were analyzed by Student's paired $t$ test, whereas differences between control and NMH-treated samples were analyzed by Student's $t$ test. d For Nox2 $2^{-l-}$ M-Kras ${ }^{\text {G12D }}$ mice, peripheral blood samples were collected 5 weeks after pIpC and analyzed for intracellular ROS levels in $\mathrm{CD}_{11 \mathrm{~b}^{+}}$cells by use of DCFDA ( $n=5$ for controls, $n=4$ for $N \mathrm{MH}$-treated mice). Peripheral blood collected 5 weeks after pIpC from M-Kras ${ }^{\mathrm{G} 12 \mathrm{D}}$ mice $(n=5)$ was analyzed in parallel, and the stainings were normalized against DCFDA staining of myeloid cells in blood of $N o x 2^{-l-} \operatorname{Kras}^{\mathrm{WT}}$ mice. Statistics by Student's $t$ test. ${ }^{*} p<0.05$, $* * p<0.01, * * * p<0.001$

cells following $N \mathrm{MH}$ treatment translated into improved aspects of immunity, we monitored T cells and NK cells in peripheral blood during the course of disease. These populations were also analysed in the bone marrow and spleen of mice at the endpoint of the experiment. It was observed that the percentage of NK cells and $\mathrm{CD}^{+}{ }^{+} \mathrm{T}$ cells in blood of M-Kras ${ }^{\mathrm{G} 12 \mathrm{D}}$ mice decreased during disease progression. In vivo treatment with $N M H$ did not significantly impact on the reduction of NK cells or T cells during the progression of leukemia (Supplementary figure $4 \mathrm{~B}$ and $\mathrm{D})$. At the end of the experiment, there were significantly fewer $\mathrm{CD}^{+} \mathrm{T}$ cells and NK cells in the spleen of $\mathrm{M}-\mathrm{Kras}^{\mathrm{G} 12 \mathrm{D}}$ mice compared with WT mice (Supplementary figure 4C, E). 


\section{In vivo treatment with $\mathrm{NMH}$ maintains genomic integrity and reduces oxidative stress in $\mathrm{M}-\mathrm{Kras}^{\mathrm{G}}{ }^{\mathrm{GD}}$ mice}

We next assessed whether the reduction in intracellular ROS levels following treatment of mice with $N \mathrm{MH}$ translated into a reduced mutation frequency in M-Kras ${ }^{\mathrm{G} 12 \mathrm{D}}$ mice. Guanine bases in DNA are sensitive to oxidation and may, when exposed to ROS, form 8-hydroxy-2'-deoxyguanosine $(8-\mathrm{OHdG})$. As $8-\mathrm{OHdG}$ tends to bind to thymidine rather than cytosine during replication, the level of 8 -OHdG is regarded as a biomarker of oxidant-induced mutagenesis [35]. We therefore used serially recovered peripheral blood myeloid cells from control or $\mathrm{NMH}$-treated M-Kras ${ }^{\mathrm{G} 2 \mathrm{D}}$ mice for analysis of $8-\mathrm{OHdG}$. The level of DNA oxidation was significantly lower in $\mathrm{NMH}$-treated animals 3 weeks after pIpC injections (Fig. 4b).

We next investigated if the reduced DNA oxidation in myeloid cells following $N \mathrm{MH}$ treatment translated into protection against DNA double-stranded breaks (DSB). As the formation of DSB entails phosphorylation of the histone $\mathrm{H} 2 \mathrm{AX}$, the resulting phosphorylated protein gamma-H2AX reportedly reflects DSB [36]. Peripheral blood samples from $N \mathrm{MH}$-treated and control M-Kras ${ }^{\mathrm{G} 12 \mathrm{D}}$ mice were analyzed for gamma-H2AX expression. Similarly to the 8-OHdG results, there was a decrease in the amount of DSBs in the blood of $N \mathrm{MH}$-treated mice that reached significance at 5 weeks after pIpC injections (Fig. 4c).

Myeloid cells isolated from the bone marrow and spleen of endpoint M-Kras ${ }^{\mathrm{G} 12 \mathrm{D}}$ mice showed excess 8-OHdG and gamma-H2AX expression staining compared with bone marrow and spleen cells of $\mathrm{Kras}^{\mathrm{WT}}$ littermates and compared with bone marrow and spleen cells from endpoint Nox2 ${ }^{-1-} \mathrm{M}-\mathrm{Kras}^{\mathrm{G} 12 \mathrm{D}}$ mice. 8-OHdG and gamma-H2AX expression levels in bone marrow and spleen cells did not differ between $\mathrm{NMH}$-treated and control M-Kras ${ }^{\mathrm{G} 12 \mathrm{D}}$ mice at the endpoint of leukemia progression (Supplementary figure 3).

\section{Discussion}

KRAS mutations in myeloid cells are associated with myeloproliferative disease in humans and mice. As mutated RAS has proven difficult to target directly [10], strategies to inhibit cellular functions that are induced by oncogenic RAS is a conceivable alternative in treating RAS-related leukemogenesis. In this study, we assessed the antileukemic properties of NOX2 inhibition in mice carrying $\operatorname{Kras}^{\mathrm{G} 12 \mathrm{D}}$ in hematopoietic cells (M-Kras ${ }^{\mathrm{G} 12 \mathrm{D}}$ ). A first finding was that myeloid cells that accumulated in $\mathrm{M}$ $\operatorname{Kras}^{\mathrm{G} 12 \mathrm{D}}$ expressed functional NOX2 and thus produced significant amounts of ROS. In vitro studies showed that
$N \mathrm{MH}$, a histamine analogue with affinity at $\mathrm{H}_{2} \mathrm{R}$, significantly reduced ROS formation in the expanding leukemic cells acting via $\mathrm{H}_{2} \mathrm{R}$.

During the progression of leukemia, the ROS levels of the myeloid cells gradually increased. Treatment of MKras $^{\mathrm{G} 12 \mathrm{D}}$ mice with $\mathrm{NMH}$ reduced the formation of ROS in vivo and significantly delayed the expansion of leukemia along with prolonging survival. At the endpoint of leukemia progression, there was no difference between ROS levels in myeloid cells of bone marrow or spleen of $\mathrm{NMH}$-treated and control M-Kras ${ }^{\mathrm{G} 12 \mathrm{D}}$ mice, which likely is explained by the limited duration of treatment (5 weeks) and by the prolonged survival of $\mathrm{NMH}$-treated mice. In addition, myeloproliferation was markedly reduced in $\mathrm{Nox}^{-1-} \mathrm{M}$ Kras $^{\mathrm{G} 12 \mathrm{D}}$ mice and the anti-leukemic properties of $N \mathrm{MH}$ were absent in these triple transgenic mice. In parallel, in vivo treatment with $N \mathrm{MH}$ as well as the genetic depletion of Nox2 significantly reduced DNA oxidation and DSB in mice carrying M-Kras ${ }^{\mathrm{G} 12 \mathrm{D}}$.

These results imply that formation of NOX2-derived ROS contributes to leukemia and mutagenesis in M$\operatorname{Kras}^{\mathrm{G} 12 \mathrm{D}}$ mice and that the targeting of NOX2 represents a conceivable anti-leukemic strategy. We cannot exclude, however, that non-NOX2-derived sources of ROS contributed to the ROS accumulation and oxidative stress observed in the proliferating $\mathrm{Kras}^{\mathrm{G} 12 \mathrm{D}}$ myeloid cells. The conclusion that $N \mathrm{MH}$ exerted anti-leukemic efficacy by targeting NOX2 was based on its inhibitory action on NOX2-dependent ROS formation and on its lack of antileukemic efficacy in $\mathrm{Nox}^{-/-}$mice, but our findings do not rule out the contribution by additional or supplementary mechanisms.

Previous studies in experimental cancer models suggest a link between RAS activation and ROS derived from various NOX species or from mitochondrial respiration [21-23]. For example, RAS expression in fibroblasts was shown to stimulate the Rac-dependent assembly of NOX1 leading to superoxide anion production and enhanced cell cycling [15]. Furthermore AKT, a kinase downstream of RAS and PI3K signaling, was shown to induce NOX4 expression and thus enhance melanoma cell proliferation [37]. However, activation of Rac or AKT may also stimulate NOX2-derived superoxide production $[38,39]$ and in the myeloid leukemia model employed in the present study the ROS levels were reduced by $>50 \%$ in $\mathrm{Nox}^{-/-}$vs. Nox $2^{+/+} \mathrm{Kras}^{\mathrm{G} 12 \mathrm{D}}$ myeloid cells. Hence, NOX2 appears to be a dominant source of ROS in myeloid cells in the $\operatorname{Kras}^{\mathrm{G} 12 \mathrm{D}}$ model of myeloproliferative disease.

Unexpectedly, only pharmacological, but not genetic, inhibition of NOX2 prolonged the survival of M-Kras ${ }^{G 12 D}$ mice. This finding may imply that the complete absence of NOX2 characteristic of $N o x 2^{-/-}$mice entails a survival disadvantage in KRAS-related leukemia. NOX2 is a pivotal 
component in the defense against several microbial agents [40] and indeed, the triple transgenic mice showed increased incidence of visible infections. Although other mechanisms may be operable, we hypothesize that the lack of impact of genetic depletion of NOX2 on the survival of $\mathrm{M}-\operatorname{Kras}^{G 12 D}$ mice was related to infections that escaped detection.

Our findings add to a growing body of evidence, suggesting that the targeting of the formation of NOX2-derived ROS entails reduction of malignant tumor growth in vivo [41-44]. Although scavengers of ROS have shown discordant results by either promoting or inhibiting tumor cell growth in vivo [45-48], the specific targeting of NOX2 has been reported to reduce murine tumor growth, albeit with variable efficiency $[41,45-49]$. The mechanisms by which NOX2 inhibition impacts on tumor growth are likely multifactorial. For example, in a melanoma model of lung metastasis, $\mathrm{NOX}^{+}$myeloid cells were found to accumulate in lungs to reduce the anti-metastatic action of lunginfiltrating NK cells by generating immunosuppressive extracellular ROS. In this setting, NOX2 inhibition rescued NK cells from ROS-induced inactivation and decreased metastasis formation by favoring immune-mediated clearance of melanoma cells [42]. Inhibition of NOX2-derived ROS has also been implicated in the differentiation and maturation of myeloid cells [41], and experiments using immunodeficient mice imply that inhibition of NOX2 reduces expansion of xenografted human cancer cells also in the absence of functional lymphocyte-mediated immunity [50, 51]. In addition, ROS, including NOX2-derived ROS, have been implicated in enhancing cell cycle proliferation and in increasing mutagenesis [52-54].

Although details regarding the anti-leukemic action of NOX2 inhibition in Kras-mutated mice remain to be defined, the phenotypic analysis of NK cells and T cells did not support improved immune surveillance during NOX2 inhibition in this model. Instead, our results point toward protection against ROS-induced oxidation of DNA in myeloid cells as a principal mechanism explaining the antileukemic activity of genetic and pharmacological targeting of NOX2. This assumption is in line with previous studies showing that treatment with $\mathrm{N}$-acetyl cysteine, which exerts antioxidant activity by augmenting cellular thiols, reduces DSBs and facilitates non-homologous end joining repair in bone marrow cells in a murine NRAS/BCL2-related model of leukemia [22]. Also, other genetic alterations that entail aberrant activation of signal transduction pathways, including $B C R-A B L$ in chronic myeloid leukemia and FLT3/ITD in AML, are associated with elevated ROS formation in hematopoietic cells [19, 55], and enhanced levels of intracellular ROS have been proposed to enhance doublestranded DNA breaks and genomic instability to propagate leukemia also in these myeloid malignancies [20, 21].
In conclusion, the results of this study suggest (i) that NOX2-derived ROS may contribute to leukemic expansion in mice carrying hematopoietic cells with mutated Kras and (ii) that strategies to target NOX2 merit further evaluation in $R A S$-mutated leukemia.

\section{Materials and methods}

\section{Genetically modified mice and experimental design}

B6.129S4-Kras ${ }^{\mathrm{tm} 4 \mathrm{Tyj} / J}, \quad$ B6.Cg-Tg(Mx1-cre) $1 \mathrm{Cgn} / \mathrm{J}$, and B6.129S6-Cybb $b^{\text {tmlDin }}$ mice were obtained from Jackson Laboratories (USA) and maintained under specific pathogen-free conditions. B6.129S4-Kras ${ }^{\mathrm{tm} 4 \mathrm{Tyj}} / \mathrm{J}$ mice carry a Lox-Stop-Lox (LSL) termination sequence followed by the $\operatorname{Kras}^{\mathrm{G} 12 \mathrm{D}}$ point mutation. When bred to the B6.Cg-Tg (Mx1-cre)1Cgn/J strain, which expresses Cre recombinase under the control of the Mx1 promoter, i.p. injection of pIpC (Sigma-Aldrich, St Louis, USA) induces endogenous interferon production that activates the Cre recombinase in hematopoietic cells with ensuing deletion of the transcriptional termination sequence, allowing for expression of oncogenic Kras in hematopoietic cells (M-Kras ${ }^{\mathrm{G} 12 \mathrm{D}}$ mice) [30].

To study the role of NOX2 in this model, B6.129S6$C_{y b} b^{\text {tmIDin }}\left(\right.$ Nox $\left.^{-l-}\right)$ mice that lack the myeloid gp91 ${ }^{\text {phox }}$ subunit NOX2, and thus a functional NOX2, were bred to B6.129S4-Kras ${ }^{\mathrm{tm} 4 \mathrm{Tyj} / \mathrm{J}}$ mice to generate $\mathrm{Nox2}^{-1-} \mathrm{Kras}^{\mathrm{G} 12 \mathrm{D}}$

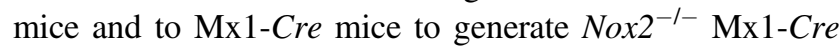
mice. These mice were backcrossed at least three times to achieve offspring with close genetic identity. Finally,

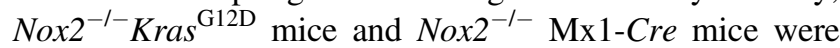
mated to generate Nox2 $^{-1-}$ LSL-Kras ${ }^{\mathrm{G} 12 \mathrm{D}} \mathrm{Mx1-Cre}$ (Nox2 ${ }^{-/-} \mathrm{M}-\mathrm{Kras}^{\mathrm{G} 12 \mathrm{D}}$ ) mice. Lack of functional NOX2 in these mice was confirmed by genotyping for Nox 2 using PCR and by measuring the lack of NOX2-dependent ROS production with chemiluminescence (Supplementary figure 1A, B).

Genotyping, as detailed below, was employed to identify double and triple transgenic pups. Three to four weeks old double transgenic M-Kras ${ }^{\mathrm{G} 12 \mathrm{D}}$ or triple transgenic Nox2 ${ }^{-/-}$ $\mathrm{M}-\operatorname{Kras}^{\mathrm{G} 12 \mathrm{D}}$ mice received three doses of pIpC $(250 \mu \mathrm{g})$ i.p. every second day starting 1 week after the first pIpC injection and continuing for 5 weeks, M-Kras ${ }^{\mathrm{G} 12 \mathrm{D}}$ or Nox2 ${ }^{-1-} \mathrm{M}-\mathrm{Kras}^{\mathrm{G} 12 \mathrm{D}}$ mice were treated with NMH (Sigma) ( $250 \mu \mathrm{g} / \mathrm{mouse})$ i.p. every second day using vehicle-treated mice $(\mathrm{NaCl})$ as controls. Activation of a recombined $\operatorname{Kras}^{\mathrm{G} 12 \mathrm{D}}$ allele was confirmed by PCR analysis of peripheral blood 2 weeks after pIpC injections. Mice were weighed and blood was collected every second week to follow the course of disease. Blood counts were determined on a Sysmex KX-21 Hematology Analyzer (Sysmex, Kobe, Japan). When moribund, mice were anesthetized and killed 
by cervical dislocation followed by recovery of spleen, bone marrow, and thymus. All experiments were approved by the Research Animal Ethics Committee at the University of Gothenburg, Sweden (application no. 86/14).

\section{Genotyping}

Genomic DNA was extracted from mouse ear biopsies of 3week-old pups for PCR analysis using the mouse direct PCR kit (Biotool, Houston, USA). The following primers were used for detection of the Nox $2^{-1-}$ allele, $\operatorname{Kras} 2^{\mathrm{LSL}}$ allele, $\operatorname{Kras} 2^{\mathrm{G} 12 \mathrm{D}}$ allele and the Mx1-Cre allele:

F-Nox $2^{-1-}$ and Nox $2^{\text {WT }}$ AAGAGAAACTCCTCTG CTGTGAA

R-Nox $2^{\text {WT }}$ : CGCACTGGAACCCCTGAGAAAGG

R-Nox $2^{-1-}:$ GTTCTAATTCCATCAGAAGCTTATCG

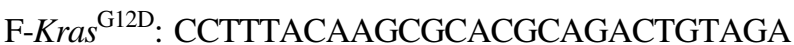

R-Kras ${ }^{\text {G12D: }}$ AGCTAGCCACCATGGCTTGAGTAAG TCTGCA

F-Mx1-Cre: GTTTCAATTCTCCTCTGGAAGG

R-Mx1-Cre: CTAGAGCCTGTTTTGCACGTTC

F- ras $^{\text {LSL }}$ : TCCGAATTCAGTGACTACAGATGTAC AGAG

R-Kras ${ }^{\text {LSL }}$ GGGTAGGTGTTGGGATAGCTG

\section{Cell preparation}

Single-cell suspensions of splenocytes and thymic cells were prepared by mashing tissues through a $70-\mu \mathrm{m}$ cell strainer. For the isolation of bone marrow cells, the femur, tibia, and hip bones were mechanically cleaned from surrounding tissue and rinsed briefly in $70 \%$ ethanol followed by phosphate-buffered saline (PBS). The clean bones were crushed with mortar and pestle in PBS. The cell mixture was filtered through a 40- $\mu \mathrm{m}$ filter and washed three times in PBS. Erythrocytes in the cell lysates were depleted using the RBC Lysing buffer (SigmaAldrich, Steinheim, Germany). $\mathrm{Gr}^{+}$cells, at a minimum of 95\% purity, were isolated from single-cell spleen suspensions using biotinylated Gr1 antibodies followed by streptavidinconjugated MACS beads (Miltenyi Biotec, Lund, Sweden) according to the manufacturer's instructions.

\section{Flow cytometry}

The following fluorochrome-labeled anti-mouse mAbs were, unless otherwise stated, purchased from BD Biosciences: anti-CD11c (HL3), anti-IaIe (2G9), anti-CD3(1452311), anti-CD4 (RM4-5), anti-CD8 (53-6.7), anti-NK1.1 (PK136), anti-CD335 (29A1.4-eBiosciences), anti-CD19 (1D3), anti-CD11b (M1/70), anti-Gr1 (RB6-8C5), anti-F4/ 80 (BM8-Biolegend) and anti-Ly6C (AL-21). In addition, LIVE/DEAD $^{\circledR}$ Fixable Yellow Dead Cell Stain Kit (Invitrogen) and diamidino-2-phenylindole (DAPI) (Invitrogen) were used for flow cytometric assessment. A minimum of 100,000 gated live cells were collected on a five-laser BD LSRFortessa $(355,405,488,532$, and $640 \mathrm{~nm}$; BD Biosciences). Data were analyzed using the FACSDiva Version 8.0.1 software (BD Biosciences).

\section{Detection of ROS by chemiluminescence}

Superoxide anion production was determined by the use of isoluminol-ECL, as previously described [56]. $\mathrm{Gr}^{+}$cells were suspended to $20 \times 10^{4}$ cells/ml in Krebs-Ringer glucose buffer supplemented with isoluminol $(10 \mathrm{mg} / \mathrm{ml}$; Sigma-Aldrich) and horseradish peroxidase $(4 \mathrm{U} / \mathrm{ml}$; Boehringer Mannheim, Mannheim, Germany) and added to a 96-well plate. The formyl peptide receptor agonist WKYMVm $\left(10^{-7} \mathrm{M}\right.$ Tocris Bioscience, Bristol, UK) was added to stimulate NOX2-derived ROS production, and light emission reflecting superoxide production was recorded continuously using a FLUOstar Omega plate reader (BMG, Ortenberg, Germany). These experiments were performed in the presence or absence of $\mathrm{NMH}$, added $5 \mathrm{~min}$ before the addition of WKYMVm. In some experiments, the histamine $\mathrm{H}_{2} \mathrm{R}$ antagonist ranitidine (Glaxo, Gothenburg, Sweden) was added prior to $N M H$ stimulation to ensure the receptor specificity of $\mathrm{NMH}$.

\section{Detection of ROS by DCFDA}

Peripheral blood or bone marrow cells were first stained for expression of CD11b (M1/70) using a fluorochromeconjugated antibody. The cells were then incubated 30 min at $37^{\circ} \mathrm{C}$ with $4.7 \mu \mathrm{M}$ DCFDA in RPMI 1640 medium (Merck Millipore, Berlin, Germany). Cells were washed and analyzed by flow cytometry in the presence of DAPI for exclusion of dead cells.

\section{Detection of DNA strand breaks and oxidated DNA}

Peripheral blood or bone marrow cells were fixed and permeabilized for $20 \mathrm{~min}$ with the fixation/permeabilization concentrate (eBioscience $^{\mathrm{TM}}$, San Diego, USA). Following washing in permeabilization buffer twice, cells were incubated at room temperature for $30 \mathrm{~min}$ with anti-H2AX (pS139; BD Biosciences) for detection of DSA or an anti-8 hydroxyguanosine antibody (Abcam) for detection of oxidative stress on DNA [35, 36]. Data were collected on a five-laser BD LSRFortessa (355, 405, 488, 532, and 640 nm; BD Biosciences).

\section{Statistical analysis}

For the animal experiments, the sample size was dependent on the availability of mice of a similar age and with a 
specified genetic profile; hence double transgenic (LSL$\mathrm{Kras}^{\mathrm{G} 12 \mathrm{D}} \times \mathrm{Mx1}$-Cre) and in particular triple transgenic $\left(\mathrm{Nox}^{-1-} \mathrm{LSL}^{-\mathrm{Kras}}{ }^{\mathrm{G} 12 \mathrm{D}} \times \mathrm{Mx} 1-\mathrm{Cre}\right)$ mice. All in vivo experiments were performed at least three times.

Animals were randomly assigned to treatment or control groups and codes were ascribed to each animal. Analyses were performed in a single blinded fashion, as the investigator assessing the treatment outcome was not aware of which mouse that received which treatment. According to ethical regulations, mice with visible infections were killed and thus excluded from analysis.

Graphpad Prism (version 7, San Diego, CA) was used for statistical analysis. For group comparisons, two-tailed paired or unpaired $t$ tests were used. For multiple comparisons one-way analysis of variance was used followed by the Bonferroni multiple comparison test. All statistical tests were two-sided, and - values below 0.05 were considered statistically significant.Funding informationThis work was supported by the Swedish Research Council, the Swedish Society for Medical Research, the Swedish Society of Medicine, the Swedish Cancer Society (Cancerfonden), the Swedish state via the ALF agreement, the Erna and Victor Hasselblad Foundation, the Torsten and Ragnar Söderberg Foundation, the IngaBritt and Arne Lundberg Foundation, the Assar Gabrielsson Foundation, BioCARE-a National Strategic Research Program at University of Gothenburg and the Sahlgrenska Academy at University of Gothenburg.

\section{Compliance with ethical standards}

Conflict of interest H.G.W., K.H., and A.M. are authors of issued or pending patents protecting the use of histamine dihydrochloride in cancer immunotherapy. The remaining authors declare no conflicts of interest.

Open Access This article is licensed under a Creative Commons Attribution 4.0 International License, which permits use, sharing, adaptation, distribution and reproduction in any medium or format, as long as you give appropriate credit to the original author(s) and the source, provide a link to the Creative Commons license, and indicate if changes were made. The images or other third party material in this article are included in the article's Creative Commons license, unless indicated otherwise in a credit line to the material. If material is not included in the article's Creative Commons license and your intended use is not permitted by statutory regulation or exceeds the permitted use, you will need to obtain permission directly from the copyright holder. To view a copy of this license, visit http://creativecommons. org/licenses/by/4.0/.

\section{References}

1. Prior IA, Lewis PD, Mattos C. A comprehensive survey of Ras mutations in cancer. Cancer Res. 2012;72:2457-67.

2. Ward AF, Braun BS, Shannon KM. Targeting oncogenic Ras signaling in hematologic malignancies. Blood. 2012;120:3397406.
3. Quinlan MP, Settleman J. Isoform-specific ras functions in development and cancer. Future Oncol. 2009;5:105-16.

4. Hancock JF. Ras proteins: different signals from different locations. Nat Rev Mol Cell Biol. 2003;4:373-84.

5. Van Etten RA, Shannon KM. Focus on myeloproliferative diseases and myelodysplastic syndromes. Cancer Cell. 2004;6:54752.

6. Bowen DT, Frew ME, Hills R, Gale RE, Wheatley K, Groves MJ, et al. RAS mutation in acute myeloid leukemia is associated with distinct cytogenetic subgroups but does not influence outcome in patients younger than 60 years. Blood. 2005;106:2113-9.

7. Loh ML. Recent advances in the pathogenesis and treatment of juvenile myelomonocytic leukaemia. $\mathrm{Br} \quad \mathrm{J}$ Haematol. 2011;152:677-87.

8. Zeng M, Lu J, Li L, Feru F, Quan C, Gero TW, et al. Potent and selective covalent quinazoline inhibitors of KRAS G12C. Cell Chem Biol. 2017;24:1005-16 e3.

9. Gysin S, Salt M, Young A, McCormick F. Therapeutic strategies for targeting ras proteins. Genes Cancer. 2011;2:359-72.

10. Scott AJ, Lieu CH, Messersmith WA. Therapeutic approaches to RAS Mutation. Cancer J. 2016;22:165-74.

11. Will M, Qin AC, Toy W, Yao Z, Rodrik-Outmezguine V, Schneider C, et al. Rapid induction of apoptosis by PI3K inhibitors is dependent upon their transient inhibition of RAS-ERK signaling. Cancer Discov. 2014;4:334-47.

12. Vachhani $\mathrm{P}$, Bose $\mathrm{P}$, Rahmani $\mathrm{M}$, Grant S. Rational combination of dual PI3K/mTOR blockade and Bcl-2/-xL inhibition in AML. Physiol Genom. 2014;46:448-56.

13. Gritsman K, Yuzugullu H, Von T, Yan H, Clayton L, Fritsch C, et al. Hematopoiesis and RAS-driven myeloid leukemia differentially require PI3K isoform p110alpha. J Clin Invest. 2014;124:1794-809.

14. Lyubynska N, Gorman MF, Lauchle JO, Hong WX, Akutagawa JK, Shannon K, et al. A MEK inhibitor abrogates myeloproliferative disease in Kras mutant mice. Sci Transl Med. 2011;3:76ra27.

15. Irani K, Xia Y, Zweier JL, Sollott SJ, Der CJ, Fearon ER, et al. Mitogenic signaling mediated by oxidants in Ras-transformed fibroblasts. Science. 1997;275:1649-52.

16. Wu RF, Terada LS. Ras and Nox: linked signaling networks? Free Radic Biol Med. 2009;47:1276-81.

17. Moiseeva O, Bourdeau V, Roux A, Deschenes-Simard X, Ferbeyre G. Mitochondrial dysfunction contributes to oncogeneinduced senescence. Mol Cell Biol. 2009;29:4495-507.

18. Mitsushita J, Lambeth JD, Kamata T. The superoxide-generating oxidase Nox 1 is functionally required for Ras oncogene transformation. Cancer Res. 2004;64:3580-5.

19. Sattler M, Verma S, Shrikhande G, Byrne CH, Pride YB, Winkler $\mathrm{T}$, et al. The BCR/ABL tyrosine kinase induces production of reactive oxygen species in hematopoietic cells. J Biol Chem. 2000;275:24273-8.

20. Sallmyr A, Fan J, Datta K, Kim KT, Grosu D, Shapiro P, et al. Internal tandem duplication of FLT3 (FLT3/ITD) induces increased ROS production, DNA damage, and misrepair: implications for poor prognosis in AML. Blood. 2008;111:3173-82.

21. Sallmyr A, Fan J, Rassool FV. Genomic instability in myeloid malignancies: increased reactive oxygen species (ROS), DNA double strand breaks (DSBs) and error-prone repair. Cancer Lett. 2008;270:1-9.

22. Rassool FV, Gaymes TJ, Omidvar N, Brady N, Beurlet S, Pla M, et al. Reactive oxygen species, DNA damage, and error-prone repair: a model for genomic instability with progression in myeloid leukemia? Cancer Res. 2007;67:8762-71.

23. Weyemi U, Lagente-Chevallier O, Boufraqech M, Prenois F, Courtin F, Caillou B, et al. ROS-generating NADPH oxidase 
NOX4 is a critical mediator in oncogenic H-Ras-induced DNA damage and subsequent senescence. Oncogene. 2012;31:1117.

24. Dikalov S. Cross talk between mitochondria and NADPH oxidases. Free Radic Biol Med. 2011;51:1289-301.

25. Bedard K, Krause KH. The NOX family of ROS-generating NADPH oxidases: physiology and pathophysiology. Physiol Rev. 2007;87:245-313.

26. Aurelius J, Hallner A, Werlenius O, Riise R, Mollgard L, Brune $\mathrm{M}$, et al. NOX2-dependent immunosuppression in chronic myelomonocytic leukemia. J Leukoc Biol. 2017;102:459-66.

27. Aurelius J, Martner A, Brune M, Palmqvist L, Hansson M, Hellstrand $\mathrm{K}$, et al. Remission maintenance in acute myeloid leukemia: impact of functional histamine $\mathrm{H} 2$ receptors expressed by leukemic cells. Haematologica. 2012;97:1904-8.

28. Aurelius J, Thoren FB, Akhiani AA, Brune M, Palmqvist L, Hansson M, et al. Monocytic AML cells inactivate antileukemic lymphocytes: role of NADPH oxidase/gp91(phox) expression and the PARP-1/PAR pathway of apoptosis. Blood. 2012;119:5832-7.

29. Saitoh T, Fukushima Y, Otsuka H, Ishikawa M, Tamai M, Takahashi $\mathrm{H}$, et al. Effects of $\mathrm{N}$-alpha-methyl-histamine on human $\mathrm{H} 2$ receptors expressed in CHO cells. Gut. 2002;50:786-9.

30. Braun BS, Tuveson DA, Kong N, Le DT, Kogan SC, Rozmus J, et al. Somatic activation of oncogenic Kras in hematopoietic cells initiates a rapidly fatal myeloproliferative disorder. Proc Natl Acad Sci USA. 2004;101:597-602.

31. Betten $\AA$, Dahlgren C, Hermodsson S, Hellstrand K. Histamine inhibits neutrophil NADPH oxidase activity triggered by the lipoxin A4 receptor-specific peptide agonist Trp-Lys-Tyr-MetVal-Met. Scand J Immunol. 2003;58:321-6.

32. Brittain RT, Daly MJ. A review of the animal pharmacology of ranitidine--a new, selective histamine H2-antagonist. Scand J Gastroenterol Suppl. 1981;69:1-9.

33. Hansson M, Asea A, Ersson U, Hermodsson S, Hellstrand K. Induction of apoptosis in NK cells by monocyte-derived reactive oxygen metabolites. J Immunol. 1996;156:42-7.

34. Hellstrand K, Asea A, Dahlgren C, Hermodsson S. Histaminergic regulation of NK cells. Role of monocyte-derived reactive oxygen metabolites. J Immunol. 1994;153:4940-7.

35. Valavanidis A, Vlachogianni T, Fiotakis C. 8-hydroxy-2'-deoxyguanosine (8-OHdG): a critical biomarker of oxidative stress and carcinogenesis. J Environ Sci Health Part C. 2009;27:120-39.

36. Kuo LJ, Yang LX. Gamma-H2AX - a novel biomarker for DNA double-strand breaks. Vivo. 2008;22:305-9.

37. Govindarajan B, Sligh JE, Vincent BJ, Li M, Canter JA, Nickoloff $\mathrm{BJ}$, et al. Overexpression of Akt converts radial growth melanoma to vertical growth melanoma. J Clin Invest. 2007;117:719-29.

38. Hoyal CR, Gutierrez A, Young BM, Catz SD, Lin JH, Tsichlis $\mathrm{PN}$, et al. Modulation of p47PHOX activity by site-specific phosphorylation: Akt-dependent activation of the NADPH oxidase. Proc Natl Acad Sci. 2003;100:5130-5.

39. Hordijk PL. Regulation of NADPH oxidases: the role of Rac proteins. Circ Res. 2006;98:453-62.

40. Rada B, Leto TL. Oxidative innate immune defenses by Nox/ Duox family NADPH oxidases. Contrib Microbiol. 2008;15:16487.
41. Martner A, Wiktorin HG, Lenox B, Ewald Sander F, Aydin E, Aurelius $\mathrm{J}$, et al. Histamine promotes the development of monocyte-derived dendritic cells and reduces tumor growth by targeting the myeloid NADPH oxidase. J Immunol. 2015;194:5014-21.

42. Aydin E, Johansson J, Nazir FH, Hellstrand K, Martner A. Role of NOX2-derived reactive oxygen species in NK cell-mediated control of murine melanoma metastasis. Cancer Immunol Res. 2017;5:804-11.

43. Grauers Wiktorin H, Nilsson T, Aydin E, Hellstrand K, Palmqvist $\mathrm{L}$, Martner. A role of NOX2 for leukaemic expansion in a murine model of BCR-ABL1(+) leukaemia. $\mathrm{Br} \mathrm{J}$ Haematol. 2017;182:290-4.

44. Kelkka T, Pizzolla A, Laurila JP, Friman T, Gustafsson R, Kallberg E, et al. Mice lacking NCF1 exhibit reduced growth of implanted melanoma and carcinoma tumors. PLoS ONE. 2013;8: e84148.

45. De Flora S, D'Agostini F, Masiello L, Giunciuglio D, Albini A. Synergism between $\mathrm{N}$-acetylcysteine and doxorubicin in the prevention of tumorigenicity and metastasis in murine models. Int $\mathrm{J}$ Cancer. 1996;67:842-8.

46. Le Gal K, Ibrahim MX, Wiel C, Sayin VI, Akula MK, Karlsson C, et al. Antioxidants can increase melanoma metastasis in mice. Sci Transl Med. 2015;7:308re8.

47. Sayin VI, Ibrahim MX, Larsson E, Nilsson JA, Lindahl P, Bergo MO. Antioxidants accelerate lung cancer progression in mice. Sci Transl Med. 2014;6:221ra15.

48. Piskounova E, Agathocleous M, Murphy MM, Hu Z, Huddlestun SE, Zhao Z, et al. Oxidative stress inhibits distant metastasis by human melanoma cells. Nature. 2015;527:186-91.

49. Ligtenberg MA, Cinar O, Holmdahl R, Mougiakakos D, Kiessling R. Methylcholanthrene-induced sarcomas develop independently from NOX2-derived ROS. PLoS ONE. 2015;10:e0129786.

50. Kiffin, R, H Grauers Wiktorin, M Nilsson, J Aurelius, E Aydin, B Lenox, et al. "Anti-leukemic properties of histamine in monocytic leukemia: Role of NOX2." Front Oncol. 2018;8:218.

51. Marlein CR, Zaitseva L, Piddock RE, Robinson SD, Edwards DR, Shafat MS, et al. NADPH oxidase-2 derived superoxide drives mitochondrial transfer from bone marrow stromal cells to leukemic blasts. Blood. 2017;130:1649-60.

52. Szatrowski TP, Nathan CF. Production of large amounts of hydrogen peroxide by human tumor cells. Cancer Res. 1991;51:794-8.

53. Panieri E, Santoro MM. ROS homeostasis and metabolism: a dangerous liason in cancer cells. Cell Death Dis. 2016;7:e2253.

54. Galadari S, Rahman A, Pallichankandy S, Thayyullathil F. Reactive oxygen species and cancer paradox: To promote or to suppress? Free Radic Biol Med. 2017;104:144-64.

55. Stanicka J, Russell EG, Woolley JF, Cotter TG. NADPH oxidasegenerated hydrogen peroxide induces DNA damage in mutant FLT3-expressing leukemia cells. J Biol Chem. 2015;290:934861.

56. Dahlgren C, Karlsson A. Respiratory burst in human neutrophils. J Immunol Methods. 1999;232:3-14. 